\title{
The Influences of Age and Power Relations on Vietnamese Tertiary Students of Non-English Majors in Making Spoken Invitations in English
}

\author{
Nguyen Trong Nhan (Corresponding Author) \\ English Department, Ho Chi Minh City University of Transport, Ho Chi Minh City, Vietnam \\ Email: nguyentrongnhan120784@gmail.com
}

\author{
Ho Thi Lai \\ English Department, Ho Chi Minh City University of Natural Resources and Environment, Ho Chi Minh City, Vietnam \\ Email: lai6af.ho@gmail.com
}

\begin{abstract}
This article reports research on the influences of age and power relations on Vietnamese tertiary students of non-English majors in making spoken invitations in English. The investigation also captures the need for socially oriented explanations of the English language learning and using through the speech act of inviting. The study found that these learners' ways of inviting are significantly affected by the Vietnamese culture. In the act of inviting a 23-year-old teacher of English to the class exhibition or graduation party, all students interviewed made their invitations formally, hesitantly and indirectly to show their politeness and respect towards the invitee who has power or authority over them. In the situation of inviting a fifty-year-old acquaintance to a birthday party or a concert, 17 participants out of 20 gave tentative expressions to the invitee who is much older than they are. The results also show that the students regarded themselves as the subordinates to an acquaintance who is on a level with their parents in the Vietnamese system of hierarchy; therefore, they used humble language with conventional terms of addressing (uncle and auntie) to the invitee and expressed their concern about the invitee's health condition. In the context of inviting a close friend or a classmate at the same age to have a cup of coffee, the subjects reveal their beat-about-the-bush style of speaking.
\end{abstract}

Index Terms - inviting, English, age, power relations

\section{INTRODUCTION}

Many researchers state that the combination of linguistic perspective and socio-cultural perspective is crucial to a successful leaner (Boxer \& Pickering, 1995; Brown \& Levinson, 1987; Coates \& Cameron, 1988). Wardhaugh (1998) points out the relationship between the sounds, words, syntax of a language and the ways in which speakers of that language experience the world and behave. He also confirms that learners ought to take into account the interwoven relationship between language and culture, and must "maintain" that they are "inextricably related". "Learners could not understand or appreciate the one without a knowledge of the other" (1998, p. 216).

Daily communication always involves invitations and people often perform the act of inviting to maintain their necessary relationships or to show their care towards other people. Nevertheless, Vietnamese students often encounter some socio-pragmatic failure in making English invitations because of the impacts of Vietnamese culture on their English use (Nguyen, 1996; Nguyen, 2001; Tran, 1990; Tran, 1995). An example of Vietnamese EFL learners' failure in making English invitations is their repetition of inviting. It is inappropriate to repeat inviting someone in English after getting his/her refusal, but in the Vietnamese culture, inviters should repeat their invitations up to three times to express their hospitality and sincerity to the invitee who has power over them (Tran, 1997).

Most ESL and EFL learners study English in their own cultural situations and thus the opportunities of being exposed to the target socio-cultural environment are limited. How contexts of learning differ and how the cultural and social characteristics of EFL/ESL learners influence their target language use in different contexts need exploring to get a full complex picture of English language learning. This paper aims to clarify and discuss the influences of Vietnamese culture in general, age and power relations in particular, on Vietnamese non-English-majored students' ways of using English through the speech act of inviting.

\section{LITERATURE REVIEW}

The speech act of inviting has been studied in various aspects, especially in the light of Cross-cultural or Contrastive Linguistics, by Vietnamese researchers (Nguyen, 1996; Nguyen, 2001; Tran, 1990; Tran, 1995), but the influences of Vietnamese socio-cultural factors on the ways Vietnamese learners use English have not investigated carefully. In this 
investigation, the researchers do not aim to compare and contrast invitations in Vietnamese and in English but focus on exploring English invitations by Vietnamese learners from the Sociolinguistic perspective.

\section{A. Speech Act Theory}

To Yule (1998, p. 25), speech act is "the basic unit of linguistic communication" and "an action performed by the use of an utterance to communicate". When people try to express themselves, they do not only produce utterances containing grammatical structures and words, but also perform actions via those utterances such as inviting, leavetaking and accusing. For instance, the utterance "Would you like a cup of coffee?" performs an act of inviting.

Hurford and Heasley (2003) state that on any occasion the action performed by producing an utterance is composed of three related acts: the locutionary act, the perlocutionary act (the perlocution), and the illocutionary act (the illocution). The perlocution of an utterance is often quite different from its illocution. Generally, the illocution performed by means of an utterance is intended by the speaker and under his control, while the perlocution is not always intended by the speaker and is not under his full control. For instance, a speaker may intend or try to carry out an illocutionary act of inviting by making an utterance, but the perlocution may be out of this speaker's control because the invitee can refuse the invitation instead of accepting it.

The following example will show that both illocutionary and perlocutionary acts are indeed related to conventions. In the Vietnamese culture, when someone says "good-bye" to an acquaintance, the common ending is "come to my house for dinner some time". Nonetheless, no Vietnamese would take it seriously because by convention this so-called invitation for dinner is just a ritual. If a Vietnamese delivers this utterance to someone from a different culture, the listener may really come the next day, and now the effect of this perlocution results from another convention that is the culture context of the listener.

\section{B. Felicity Conditions of Invitations}

As producing an utterance, the speaker normally wishes the hearer could understand his or her illocutionary meaning. This means that the speaker wants the performative in his or her speech to obtain the desired effect. To attain that efficiency, it has to satisfy certain criteria known as felicity conditions. Wardhaugh (1998) mentions three felicity conditions that performatives have to meet to be successful: Firstly, there must be a conventional procedure that specifies who the participants are, what they do and in what circumstances. Secondly, all speakers must correctly implement this procedure and carry it through to completion. Lastly, all parties must have necessary thoughts, feelings, and intentions.

Generally, to study the way people make any speech acts including inviting, many researchers consider: (1) Participants - how well they know each other and the status of their social roles, (2) the social setting - formal or informal, (3) the conversation's purpose, and (4) the conversation's topic (Brown \& Yule, 1987; Hurford \& Heasley, 2003; Leech, 1983; Schmidt \& Richards, 1980; Searle, 1975). When the inviter succeeds to clarify the above factors, s/he will find out the proper ways to invite somebody. In addition, McCarthy (1991) contends that age and the social relationship between the inviter and invitee are also decisive to language choices. Nguyen (2001) defines the felicity conditions of invitations in America as follows: The locutionary form of politeness requires the proper use of wording and conventionally appropriate terms of addressing, and the illocutionary form requires the inviter to offers hospitality to the invitee without the imposition of charges or other demands. Furthermore, the implied benefit to the invitee is addressed as if their presence constitutes the bestowal of a favor.

Tran (1997) states that to be recognized as intended, an invitation must meet the three following felicity conditions. Firstly, the inviter must be in a legitimate position to offer hospitality and sincerity. Secondly, the invitee must be able and willing to accept the invitation. Lastly, the inviter must employ appropriate word choices and imply potential benefits to the invitee. For example, to invite someone to a party for a special tea, you need to be the host and there needs to be some special tea. You must truly mean to give him a special tea if he accepts your invitation, and in case he accepts your invitation you have to get him this special tea.

\section{Politeness Theory and Its Influences on the Act of Inviting}

In its simplest explanation, politeness theory consists of the recognition and consideration of the listeners with their feelings and rights in a specific situation (Holmes, 1992). Politeness is related to using appropriate language forms and it is determined by culture-based assumptions about what it means to be polite (Wardhaugh, 1998). The illocution behind a particular polite utterance might differ completely from one culture to another. In the light of sociolinguistics, Brown and Levinson (1987) divided a polite behavior into positive politeness and negative politeness. Positive politeness is an attempt by a speaker to treat the listener as a friend or someone to be included in discourse. Negative politeness is an attempt by the speaker to save the listener's face by engaging in some formality or restraint. The notion "face" refers to the emotional and social sense of self that somebody has and expects everyone else to recognize. From Spolsky's perspective (1998, pp. 30-35), two aspects of people's feelings come into "Negative face: desires not to be imposed upon" and "Positive face: desires to be liked, admired, ratified, and related to positively".

An invitation can show different levels of politeness, especially the friendly, polite, honorable and hospitable attitudes of the addresser to the addressee. In Vietnam, people usually invite each other at least two times. If the host or the inviter only makes his or her invitation once, the guest or the invitee may think that it is an insincere invitation. 
Vietnamese people also tend to be more polite in inviting those who are socially superior or socially important to them. In addition, people are generally more polite to those whom they do not know well or "to those who are somehow socially distant: strangers, persons from very different walks of life" (Spolsky, 1998, p. 45). This particular investigation employs politeness theory to analyze the collected data and discuss the effects of age and power relations on Vietnamese learners in inviting.

\section{Ways of Prefacing Invitations in English}

In this study, the researchers would like to find out what strategies Vietnamese students adopt and adapt in their English use through the act of inviting. The investigation's framework of analysis includes the following strategies.

There are two general types of strategies (McCarthy, 1991):

(1) Direct strategies: The inviter does not preface the invitation. He/She uses less-tentative (less hesitant and more direct) expressions, for example, "Have a cup of coffee?"

(2) Indirect strategies: The inviter prefaces the invitation. He/She uses tentative (more hesitant and less direct) expressions, for example, "We're having an art exhibition next Saturday. I'm wondering if you could join us."

Isaacs and Clark (1990) and Salmani (2002) point out four principal indirect strategies of prefacing invitations as follows.

+ Grounder: The inviter informs the invitee of the setting of the invitation's occasion.

e.g. "Next Monday evening I'm going to have my birthday party at home. Can you come?"

+Pre-commitment: The inviter reduces the invitee's possibility of declining the invitation by trying to engage the invitee into a commitment to accept the invitation.

e.g. "You don't have any plans for the weekend, do you? Can you attend our party?"

+Hedge: The inviter hedges the invitation by using expressions like "I guess", "If you...", "I wonder", "maybe" and "I mean".

e.g. "If you're ever in Houston, just come and visit me."

+Flattering: The inviter tries to convince (encourage) the invitee to accept the invitation by:

- Telling the invitee how good the inviter feels if the invitee accepts the invitation.

e.g. "Your presence would be great honor for us."

- Assuring the invitee that there is no inconvenience.

e.g. "Come to visit us whenever you have time. We have plenty of rooms."

- Showing the invitee's benefit if the invitee accepts the invitation.

e.g. "It will be a good chance for you to meet famous people in our city."

- Making a strong request.

e.g. "We're having our party tonight at Riverside restaurant. Mary, you have to come!"

\section{METHODOLOGY}

A qualitative research is the study of a set of situational events that guide the interpretation of discourse (TingToomey, 1984) and qualitative researchers attempt to accurately describe, decode, and interpret the meanings of phenomena occurring in their normal social contexts (Fryer, 1991). This study is qualitative by nature because its primary task is to clarify and explain the effects of age and power relations on Vietnamese tertiary students of nonEnglish majors in making spoken invitations in English in three specific situations.

Situation 1: The invitee has the power or authority over the inviter. A last-year student, aged 22 to 23, invites his/her 23-year-old teacher of English to his/her class exhibition or graduation party.

Situation 2: There is age distance between the inviter and the invitee. A last-year student, aged 22 to 23, invites a 50year-old acquaintance to his/her birthday party or a concert.

Situation 3: There is no age and power distance between the inviter and the invitee. A student invites a close friend or classmate who is at his/her age to have a cup of coffee.

The researchers collected speech data from open-ended or unstructured interviews (Nichols, 1991) with 20 Vietnamese full-time tertiary students of non-English majors at Ho Chi Minh City University of Transport in Vietnam. These subjects consist of 10 male and 10 female last-year students between the ages of 22 and 23. Their English levels range from elementary to pre-intermediate. All of them have learnt English as a foreign language for at least seven years but they were mainly taught vocabulary, grammatical rules, reading skills, and translation strategies.

\section{A. Data Collection}

The investigators employed open-ended interviews as the only research method because of the following reasons. According to Wimmer and Dominick (1997), unstructured interviews can be used to test what people respond to a particular issue, and this may throw a completely different light on the issue that the interviewer has never considered. Moreover, freedom for the interviewees to answer the questions in the ways they wish to is important in giving them a feeling of control in the interview situation.

To Wimmer and Dominick (1997), a dominant participant can negatively affect the outcome of the group and that group pressures may influence the responses made by individuals. Therefore, one-to-one interviews were employed to 
avoid the potential impacts of one or two respondents on the remaining members of the group. Each of the 20 interviewees was put into each of the three above situations to answer a broad range of questions in any order according to how the interview developed (Breakwell, Hammond \& Fife-Schaw, 1995). To Nichols (1991, p. 131), an unstructured interview is "informal" and "not structured by a standard list of questions"; therefore, the students were free to answer the interviewer's questions and the interviewer was flexible about probing deeper into the respondent's initial response to gain a more detailed answer to each question (Wimmer \& Dominick, 1997). In other words, questions following the first one were entirely based on how the respondent's answer leaded the interview.

\section{B. Data Analysis}

The analysis of the received data includes the steps as follows. First, the primary and unstructured data was classified into three categories according to the research situations. Second, because of the varied nature of the responses, the investigators employed the content analysis technique (Wimmer \& Dominick, 1997) to analyze them. This technique was integrated with the researchers' interpretation, description and evaluation of the results. The researchers' discussion and comment about the findings were given based on the data analysis and the theoretical background.

\section{RESULTS AND DisCUSSIONS}

Situation 1: The invitee has the power or authority over the inviter. A last-year student, aged 22 to 23, invites his/her 23-year-old teacher of English to his/her class exhibition or graduation party.

All participants interviewed in this context used tentative expressions (grounder, pre-commitment, hedge, and flattering). These Vietnamese students expressed their invitations hesitantly and indirectly, for example, "Next Saturday, we're holding our class exhibition. Teacher, could you arrange your time to come?" "On be half of my class, I'd like to invite you to join us." "It's our honor if you could attend our graduation party tomorrow evening."

The results show that the Vietnamese participants apparently considered this situation a formal one; therefore, all of these speakers gave tentative expressions to show their politeness. As stated by Brown and Levinson (1987), relative power of the addressee over the speaker is one of the three elements determining the choice of language and politeness level. Talking to a teacher having some power over them, the Vietnamese learners tried to use English in a way that could avoid threatening the teacher's negative face. These students, thus, did not expect the teacher to have the feeling of being imposed. They wanted the teacher to feel free of imposition: "I'm wondering if you'd like to attend our graduation party tomorrow evening." "Are you free next Monday morning, Sir? Can you come to share the joy with us?" Besides, the phrases "if you can" and "if you are not busy" occurring in some invitations also indicate that the Vietnamese participants would like to leave the decision for the invitee. This is considered a very high level of politeness in the act of inviting in the Vietnamese culture (Tran, 1997).

The presence of "On behalf of..." in the structure of four participants' invitations is a culturally marked feature. The speaker was just a representative of his/her class. He/She is an individual in a group so s/he is responsible for not only him/herself but also the whole community. Vietnamese culture appreciates thinking and behaving for the sake of the community, thus the Vietnamese collective spirit is extremely high (Tran, 1997). According to Brown and Yule (1987), culture has tacit powerful rules for activities of both individuals and groups; it governs each individual's behaviors in a group, makes him/her sensitive to matters of status, helps him/her know what other people expect of him/her and what may happen if s/he does not live up to their expectations. Culture also helps us recognize "how far we can go as individuals" and what our responsibilities are to our "group". Different cultures are the underlying structures that make "round community round and square community square" (1987, p. 14).

In Vietnam, teaching is regarded as the first most respectful profession among the noblest ones despite the fact that a great number of Vietnamese teachers are getting unsatisfactory payments. Teachers in Vietnam have been considered the second parents or sometimes more important than the real parents and students must always hold teachers in veneration. Therefore, in the first situation, six students out of twenty dare not address the teacher as "you" alone but they used "Teacher/Madam/Sir" first to show their respect to the invitee.

Situation 2: There is age distance between the inviter and the invitee. A last-year student, aged 22 to 23, invites a fifty-year-old acquaintance to his/her birthday party or a concert.

In the Vietnamese language, the communicators' ages are very important. It is an influential element in making language choices as well as in interpreting the illocutionary meaning underlying those language choices. People with different ages have different psychological lives that may deeply affect their use of the language. However, as revealed by McCarthy (1991, p. 127) "there has been little, if any, research that has had age differences in language use as its prime focus, despite the social importance of such differences." The researchers are aware that basing on their culturally determined viewpoint, many Vietnamese EFL learners may perform the target language practices in the ways that they follow in their own society and this study's subjects' expressions of inviting might be deeply controlled by the Vietnamese socio-cultural factors.

The English language generally depicts a society of equality between you and I (Spolsky, 1998; Yule, 1998), while the Vietnamese language depicts a society of hierarchy with many different terms of addressing between people at different ages (Tran, 1997). In the second situation, the findings show that 17 participants out of 20 used tentative expressions, for example, "Uncle, please go to the concert with us. We've already bought the tickets." or "Auntie, 
you've looked tired recently. Please go to the concert with us." Actually, there were not any uncles or aunts of the informants here but in the Vietnamese language and culture, "uncle" and "auntie" are the two polite and conventional terms that are usually addressed to those who are on a level with parents in the system of hierarchy. It is clear that these Vietnamese learners' ways of using English are determined by their conventional beliefs of hierarchy.

In such a hierarchical society as Vietnam, age is also one of the factors establishing the level of power between citizens of a society in general and between members of a family in particular. Young people, as a result, are expected to speak and behave differently from what the elderly do. It is necessary that Vietnamese older people be respected by the younger regardless of social positions. Therefore, the language used by the young to the older people is usually indirect and humble with an employment of formal and respectful terms of addressing (uncle, auntie). Therefore, when a last year student, aged 22 to 23, talked to a fifty-year-old acquaintance, s/he regarded him/her the subordinates. The findings show that 17 students out of 20, who were much influenced by Confucian tenets (emphasizing the hierarchy in society), invited a fifty-year-old acquaintance tentatively to avoid losing the superior's face. In Vietnam, causing someone to lose face is considered a challenge to his/her status in the hierarchy. Nevertheless, the Confucian philosophy seems to be faded in the rest of participants (3 participants). These three informants employed much less formal and less tentative expressions, for instance, "Why don't you go to the orchestra concert with us?" "Will you go to the concert with us?" or "I'd like to invite you to the concert with us." This shows that some young Vietnamese speakers of English today can learn, acquire, and use the target language appropriately even though they are taught in the Vietnamese context.

Noticeably, eight Vietnamese inviters stated the health condition of the invitees as a grounder, "You've looked tired recently". Again, this is a conventional feature of Vietnamese tradition. Mentioning health condition of the hearer is one way to express the speaker's concern to the hearer, especially when the hearer is a middle-aged or an old Vietnamese person. One thing to remember is that when you consider the Vietnamese listener's health status, you should not mention the bad things about the fact. For example, you see that the listener has looked sick and pale these days but you should not frankly tell him/her about the truth "sick and pale", instead you should say something like "tired". The reason for this is that Vietnamese people do not want the listener to worry too much about his/her health although this is not always good for the listener.

Choosing the appropriate linguistic forms for inviting involves the dimensions of solidarity (social distance) and power (social status). Holmes (1992) states that imperatives are used between people knowing each other well or to subordinates; while interrogatives and declaratives, including hints, tend to be used between those who are less familiar with each other, or where there are some reasons to feel the task being requested is not a routine. In the act of inviting an acquaintance to a birthday party or to a concert, 16 inviters used interrogatives to the invitee who was less familiar with them. Interestingly, every student avoided using flattering, and all of them employed grounder and precommitment in their invitations to an acquaintance. These Vietnamese speakers showed that they found it distant in the relationship with an acquaintance. To Brown and Levinson (1987), when talking to an acquaintance, people focus on the negative face wants of such a person with social distance to avoid imposing on him/her. That is why these Vietnamese speakers used tentative expressions in their invitations.

Situation 3: There is no age and power distance between the inviter and the invitee. A student invites a close friend or classmate who is at his/her age to have a cup of coffee.

In the last situation, the interviews show that 15 participants out of 20 used less-tentative expressions, for example, "How about having a cup of coffee?" "Could I invite you a cup of coffee?" "Let's have some coffee now." "Do you want to get some coffee?" "Would you like to have a cup of coffee?" "Would you have a cup of coffee with me?" "Have a cup of coffee now?" "Coffee?"

Five interviewees out of 20 used tentative expressions: "Hey Long, I can invite you a cup of coffee. What do you think?" "I think a cup of hot coffee will be good for you. What do you think?" "There's a new cafeteria near here. Would you like to have a cup of coffee there?" "I'm wondering if you want a coffee now." "Do you think I can invite you a coffee?"

The above findings illustrate the fact that Vietnamese people often reveal their beat-about-the-bush style of speaking. They do not usually deliver their invitations without saying something beforehand even though they are close friends. Five Vietnamese students out of twenty gave grounder, hedge and flattering in their invitations to a classmate or close friend.

In this situation, the Vietnamese language reveals its great impacts on the Vietnamese learners' use of English. Feelings and thinking are always given the first priority in the Vietnamese mind and this is transferred into their use of English: "I think a cup of hot coffee will be good for you. What do you think?" One Vietnamese informant spoke out his/her intention beforehand and then asked for the invitee's opinion: "I can invite you a cup of coffee. What do you think?" This invitation may sounds strange to native speakers of English because the inviter translated word for word his thinking from Vietnamese into English. The question "What do you think?" here functions as a probing question and as an invitation as well. "I can" refers to not only the ability of paying for a cup of coffee but also an intention or plan. Similarly, one student said to his classmate, "Do you think I can invite you a coffee?" In terms of meaning, this expression may sound absurd or ridiculous but it is actually an acceptable way of inviting in the Vietnamese culture. 
This informal context happens between close friends or classmates; therefore, 15 participants employed less-tentative expressions. These subjects realized that minimizing social distance between close friends was an essential task. Obviously, the friendliness between the two close friends brought about the directness in the use of the target language. Therefore, to show their positive politeness to the classmates, these informants employed friendly or direct expressions. According to Spolsky (1998), being friendly with the hearer or showing concern for him/her, the speaker saved the hearer's positive face.

The friendliness and solidarity between close friends or classmates were also indicated in the way the students greeted and addressed to each other. Six students out of twenty did not use any terms of addressing at all. They just invited their classmate without calling the invitee's name or using any addressing terms, for example, "Coffee?" or "Hey, drink coffee?" In addition, three invitations employed imperative forms including the structure "Let's ..." which may be informal and casual, but are illustrations of the friendliness between close friends. As mentioned previously in this paper, Holmes (1992) states that imperatives are used between people who have known each other well.

\section{CONCLUSION}

In Speech acts and second language learning, Schmidt and Richards (1980, p. 156) conclude that speech acts are "not comparable across cultures" and each culture defined a certain conventionalized norm for interpreting each speech act. It appears that to perform the act of inviting appropriately and effectively, non-native speakers of English like the Vietnamese should not only base on linguistic forms of this act but also put it in specific situations. The results of this research show that the patterns of invitations spoken by Vietnamese EFL learners differ from this context to that context and these learners' ways of inviting are significantly affected by the Vietnamese culture. Basing on their own culturally determined viewpoint, most of this study's subjects performed the English language practices in the ways that they followed in their own native language and society. As to the process of learning, it is undeniable that social elements, such as power relations and culture-based assumptions about what it means to be polite, play an important role in development. Furthermore, an individual learner factor like the communicators' ages also weighs big impacts on the performance of the target language.

For a more complete understanding of language learning, second language learners must take into account how societal and cultural factors, whatever their different learning practices, enable their learning. Such understanding will help learners know more clearly how their own cultural practices may be harnessed to enable their learning process and progress. For this reason, both improving communicative competence and heightening the awareness of the target culture are of utmost necessity.

It is hoped that this study's findings make a positive contribution to the learning of English as a second or foreign language and to the art in ELT with special reference to the teaching of speech acts to tertiary students of non-English majors in Vietnam and some other Asian countries. The researchers also wish to see more investigations carried out to explore the influences of age and power relations on both inviters and invitees in the making of both invitations and responses.

\section{REFERENCES}

[1] Boxer, D. \& L. Pickering. (1995). Problems in the presentation of speech acts in ELT materials. ELT Journal: The case of complaints, 49(1), 45-46.

[2] Breakwell, G. M., S. Hammond \& C. Fife-Schaw. (1995). Research methods in psychology. London: Sage.

[3] Brown, G. \& G. Yule. (1987). Discourse analysis. Cambridge: Cambridge University Press.

[4] Brown, P. \& S. Levinson. (1987). Politeness: Some universals in language usage. Cambridge: Cambridge University Press.

[5] Coates, J. \& D. Cameron. (1988). Women in their speech communities: A new perspective on language and sex. London: Longman.

[6] Fryer, D. (1991). Qualitative methods in occupational psychology: Reflections upon why they are so useful but so little used. The Occupational Psychologist, 14(Special issue on qualitative methods), 3-6.

[7] Holmes, J. (1992). An introduction to sociolinguistics. London: Longman.

[8] Hurford, J. R. \& B. Heasley. (2003). Semantics a coursebook. Cambridge: Cambridge University Press.

[9] Isaacs, E. A. \& H. H. Clark. (1990). Ostensible invitations. Language In Society, 19(4), 493-509.

[10] Leech, G. (1983). Principles of pragmatics. London: Longman.

[11] McCarthy, M. (1991). Discourse analysis for language teachers. Cambridge: Cambridge University Press.

[12] Nguyen, D. P. H. (1996). Common situational structures expressing invitations in Vietnamese and in English. Unpublished graduation paper, Hue University.

[13] Nguyen, T. T. B. (2001). Inviting and responding: A cross-cultural study in American English and in Vietnamese. Unpublished graduation paper, Hue University.

[14] Nichols, P. (1991). Social survey methods. Oxford: Oxfam.

[15] Salmani, M. A. (2002). A comparative Sociopragmatic study of ostensible invitations in English and Farsi. Nodoushan: University of Tehran.

[16] Schmidt, R. \& J. C. Richards. (1980). Speech acts and second language learning. London: Longman.

[17] Searle, J. (1975). Speech Acts. Cambridge: Cambridge University Press.

[18] Spolsky, B. (1998). Sociolinguistics. Oxford: Oxford University Press. 
[19] Ting-Toomey, S. (1984). Qualitative research: An overview. In W. B. Gudykunst \& Y. Y. Kim (eds.), Methods for intercultural communication research. Beverly Hills, CA: Sage Publications, 169-184.

[20] Tran, N. T. (1997). The basics of Vietnamese culture. Vietnam: College of Social Sciences and Humanities in Ho Chi Minh City.

[21] Tran, T. T. H. (1995). Inviting in Vietnamese and in English in the context of inviting a friend to an informal party. Unpublished graduation paper, Hue University.

[22] Tran, X. T. (1990). Inviting in Vietnamese and in Australian English. Unpublished master's thesis, Open University in Ho Chi Minh City.

[23] Tsui, A. (1994). English conversation. Oxford: Oxford University Press.

[24] Wardhaugh, R. (1998). An introduction to sociolinguistics. Oxford: Oxford University Press.

[25] Webster, J. (1956). Guest list and invitations. Regents: Prentice Hall Inc.

[26] Wimmer, R. D. \& J. R. Dominick (1997). Mass media research: An introduction. Belmont, MA: Wadsworth.

[27] Yule, G. (1998). Pragmatics. Oxford: Oxford University Press.

Nguyen Trong Nhan is currently teaching English for Computing, English for Civil Engineering, and English for Mechanical Engineering at Ho Chi Minh City University of Transport, Vietnam. He earned his Master's Degree in Applied Linguistics from Curtin University of Technology, Australia, and Postgraduate Diploma in TESOL from SEAMEO RELC, Singapore. He has contributed two articles to HCMC University of Transport's Journal of Transport Technology and Science, ISSN: 1859-4263. His academic interests include sociolinguistics, second language acquisition, and applications of information technology to language teaching and learning.

Ho Thi Lai has been teaching EFL at University of Natural Resources and Environment since 2008. She finished her Master of TESOL from Victoria University, Australia, and Diploma in TESOL from Ho Chi Minh City Open University, Vietnam. Her professional interests include curriculum design, assessment, and discourse analysis. 